\title{
THE RELATIONSHIP BETWEEN COASTAL WEST AFRICAN DUST LEVEL AND CARIBBEAN ISLAND DUST
}

\author{
LOVELY EUPHRASIE-CLOTILDE, JACK MOLINIÉ, TONY FEUILLARD \& FRANCENOR BRUTE \\ Laboratory of Research on Geosciences and Energies, University of Antilles, Guadeloupe (FWI)
}

\begin{abstract}
Desert dust coming from North African sources is a major phenomenon of the atmosphere related to its impact on the earth climate and human health. A great part of this particle product is transferred in a westward flux, over the Atlantic Ocean in form of outbreaks. Depending on the season, transport conditions and meteorological configuration along the pathway, high dust concentrations can reach either the northeast coast of South America or the islands of the Caribbean region. Their arrival corresponds with bad local air quality and numerous admittances into hospital emergency rooms. The control of health risk requires a dust-level forecast using satellite, model and ground measurements data. In this study, we investigate a correlation between PM10 measurements performed in 2015 by air quality networks at two sites, one in Dakar located on the West African coast and the other in Guadeloupe, a French Caribbean Island. The PM10 dust concentrations for both sites have been obtained using the same certified instruments (TEOM). Only Guadeloupe dust events presenting a daily mean PM10 of up to $35 \mu \mathrm{g} / \mathrm{m}^{3}$ with back trajectories crossing in the vicinity of Dakar and verifying trajectories coming from Dakar, crossing close to Guadeloupe, have been taken into account. An air masses transport delay deduced by the HYSPLIT trajectory model was applied and a non-correlation between the two sites PM10 (correlation coefficient $R=0.3$ ) was observed. Using the same trajectories and back trajectories, proximity conditions and HYSPLIT delay, the two sites' Aeronet photometric measurements (AOT1020) have been compared. A good correlation confirmed by a correlation coefficient, $R=0.88$, was obtained between the Dakar AOT 1020 and the Guadeloupe AOT 1020. On the twelve dusty days of 2015 within eligible conditions of the pathway, an $80 \%$ decrease of AOT1020 during the transfer over the Atlantic Ocean was found.
\end{abstract}

Keywords: desert dust, PM10, AOT, back trajectories, long-range transport, pollution.

\section{INTRODUCTION}

Desert dust plumes coming from West Africa have regularly affected a major proportion of the Earth, and, specifically, the Caribbean region [1], [2]. Dust particle presence impacts population health, air quality and climate. Dust plumes originating in source areas located in the northern part of the Sahara (intersection between Mauritania, Mali and south of Algeria) left the African coast, then were transported over the Atlantic Ocean and reached Guadeloupe after $6000 \mathrm{~km}$ of travel. These desert dust events mainly present a seasonal variability [3]-[6]. Two seasons have been distinguished: a high dust season (May to September) and a low dust season for the rest of the year.

During 2015, very intense events have been recorded in terms of intensity and duration on Guadeloupe Island. We verified that atmospheric configurations and meteorological essential conditions have been satisfied for that natural pollution phenomenon. The transport characteristics and dusty airs masses pathway by back trajectories (HYSPLIT) for 2015 year events was studied in order to identify a particular transport behaviour linked to the NorthWest African dusts. Indeed, the most part of desert dust arriving in Guadeloupe trajectories crossed through Dakar when they left the African coast. Note that in $2015,43 \%$ of dust events impacting our region came from the North-West African area. In most cases, dusty air masses had left the African coast around $15^{\circ} \mathrm{N}$ of latitude, whilst at Dakar, they were located at $14.75^{\circ} \mathrm{N}$ and $17.17^{\circ} \mathrm{W}$. 


\subsection{Atmospheric optical thickness (AOT)}

Both Guadeloupe and Senegal have photometers integrated into the AErosol RObotic NETwork (AERONET) driven by NASA and PHOTON group. By determining the intensity of solar radiation above the atmosphere and at ground level, the atmospheric optical thickness (AOT), which is related to the presence of desert dust particles in suspension, can be evaluated. With daily measurements of AOT, we have data reliably revealing the presence of particles originating from desert areas, at the departure of dust events for Senegal data and at their arrival for Guadeloupe data. These measurements allow us to quantify the dust amount in the atmosphere at the beginning and end of their transatlantic travel.

\subsection{PM10}

Furthermore, measurements of mass concentrations in the atmosphere of particle matter with aero-dynamical diameter less than 10 microns (PM10), are provided in Guadeloupe by air quality networks Gwad'air, and in Dakar by CGAQ. These measurements are performed every second, registered every 15 minutes and can be converted to hourly and daily data. It is important to note that Caribbean region anthropogenic particle pollution is very low (around $20 \mu \mathrm{g} \mathrm{m}^{-3}$ ) and desert dust natural pollution is the main factor affecting PM10 data. However, in Dakar, the anthropogenic pollution is not insignificant because it contains dust particles put back into the atmosphere by car traffic, and can affect PM10 concentration values. Therefore, we chose a measuring station outside any industrial zones in order to evaluate better-quality data.

Carlson and Prospero [7] have previously characterized the dry air masses responsible for transporting "sand haze": the Saharan Air Layer (SAL). SAL presence is observed by detecting the presence of dry air in a layer, located between $1500 \mathrm{~m}$ and $4500 \mathrm{~m}$. To date, we cannot predict the intensity and the exact duration of the "sand haze" phenomena threatening our region. The finer particles remain suspended in the atmosphere and are transported in altitude, rather than the largest dust particles that fall faster. During their transport, part of the plumes, between 1000 and $3000 \mathrm{Mt}$ per year [2], [8], [9], are dumped into the Atlantic. The challenge is to predict the intensity of the phenomenon 3 to 10 days prior upstream, ready to leave the African coasts.

Initially, our objective is to compare the intensity of the phenomenon of pollution from the African coast to its arrival in the West Indies. Through this study, we sought to establish a correlation between PM10 data from Dakar (Senegal) and Baie-Mahault (Guadeloupe). The same study was subsequently realized with AOT data. A good correlation between the amounts of dust from Dakar and those deposited on our island, Guadeloupe, permits us to anticipate a few days before the intensity of the sand haze phenomenon in our regions.

\section{METHOD}

In our region (Guadeloupe), the air quality is mainly affected by desert dust; seasonal natural pollution. Regarding PM10, the share of anthropogenic pollution does not exceed $20 \mu \mathrm{g} \mathrm{m}^{-3}$. Therefore, we consider that from $35 \mu \mathrm{g} \mathrm{m}^{-3}$ there is the presence of desert dust particles in the atmosphere.

- First, days that exhibited a daily concentration higher than PM10 or equal to $35 \mu \mathrm{g} \mathrm{m}^{-3}$ in Guadeloupe were recorded.

- Second, their associated back trajectories were analysed. Back trajectories tell us about the origin of the dust, and the behaviour of air masses (depending on altitude) over West 
Africa and the Atlantic. To avert the error factor of uncertainty on the position of air masses with the model of HYSPLIT, the following method was used.

- Third, days presenting back trajectories crossing near (within $200 \mathrm{~km}$ ) Dakar have been selected.

On the other hand, when assessing the transport time (days), the corresponding trajectories of air masses coming from Dakar and arriving in Pointe à Pitre have been analysed. This method allowed us to select the days representing, at best, a direct transport between Dakar and Pointe-à-Pitre. For 2015, there are 12 cases that meet the following criteria:

- Daily PM10 in Guadeloupe exceeding $35 \mu \mathrm{g} \mathrm{m}^{-3}$.

- Corresponding trajectories and back trajectories passing over Dakar and Guadeloupe. For these cases, the correlations between PM10 concentration and AOT (Dakar and Pointe à Pitre) were studied.

See Figs 1 and 2 for examples.

\subsection{Correlation between Dakar PM10 data (departure) and Guadeloupe data (arrival)}

To obtain the correlation between PM10 concentration performed in Dakar and Baie-Mahault for the same event, we first studied the dust events which fulfil the prescribed requirements describe previously and obtained the data presented in Table 1. Fig. 3 presents the relation between PM10 in Dakar and PM10 in Guadeloupe performed on the same event and the calculated correlation coefficient.

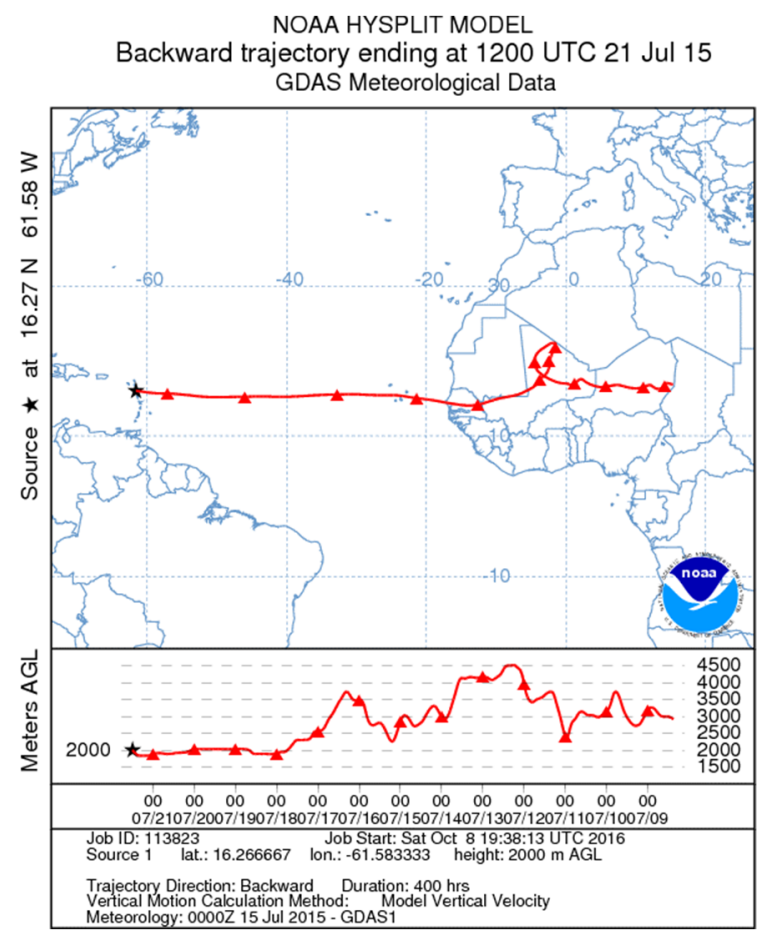

Figure 1: Back trajectory of 21 July 2015 from Baie-Mahault (elevation: 2000 m; duration: 400 hours) passing over Dakar four days before, 17 July 2015. 
NOAA HYSPLIT MODEL

Forward trajectory starting at 1200 UTC 17 Jul 15

GDAS Meteorological Data

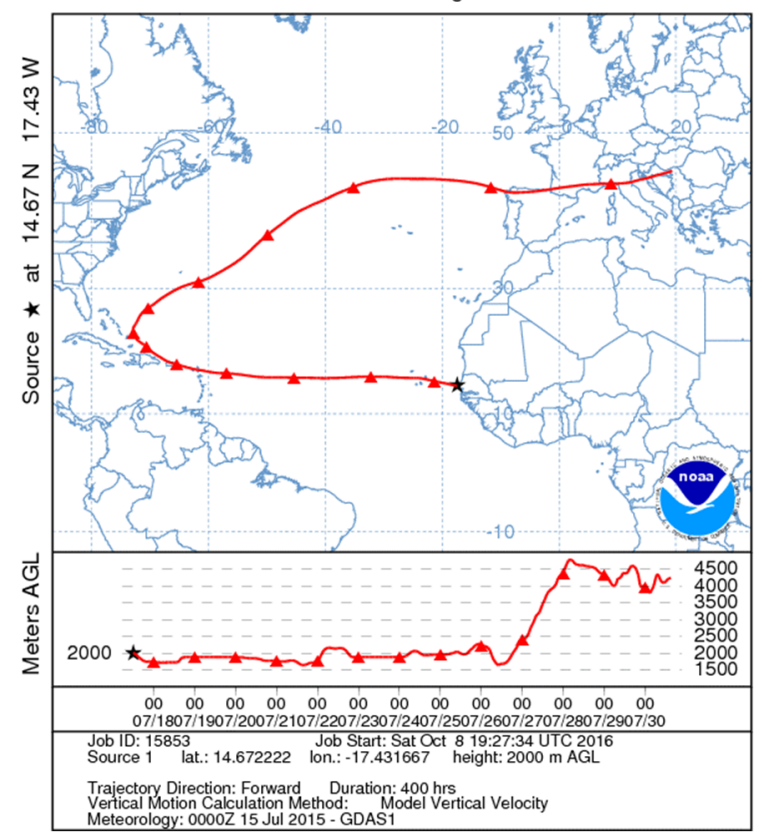

Figure 2: $\quad$ Trajectory of 17 July 2015 from Dakar (elevation: 2000 m; duration: 400 hours) passing over Guadeloupe four days later, 21 July 2015.

Table 1: PM10 data.

\begin{tabular}{|l|l|l|l|}
\hline Date & PM10 Dakar & Date & PM10 Baie-Mahault \\
\hline $16 / 05 / 2015$ & 111.48 & $22 / 05 / 2015$ & 87.9 \\
\hline $07 / 06 / 2015$ & 54.20 & $14 / 06 / 2015$ & 45.7 \\
\hline $10 / 06 / 2015$ & 99.20 & $16 / 06 / 2015$ & 46.9 \\
\hline $14 / 06 / 2015$ & Missing data & $18 / 06 / 2015$ & 68.5 \\
\hline $18 / 06 / 2015$ & 82.11 & $23 / 06 / 2015$ & 98.9 \\
\hline $20 / 06 / 2015$ & 52.87 & $26 / 06 / 2015$ & 53.6 \\
\hline $28 / 06 / 2015$ & 49.16 & $03 / 07 / 2015$ & 68.1 \\
\hline $07 / 07 / 2015$ & 94.65 & $14 / 07 / 2015$ & 47.0 \\
\hline $17 / 07 / 2015$ & 58.53 & $21 / 07 / 2015$ & 54.6 \\
\hline $18 / 07 / 2015$ & 40.02 & $23 / 07 / 2015$ & 64.7 \\
\hline $21 / 07 / 2015$ & 69.77 & $28 / 07 / 2015$ & 54.5 \\
\hline $10 / 08 / 2015$ & 30.03 & $21 / 08 / 2015$ & 49.3 \\
\hline
\end{tabular}




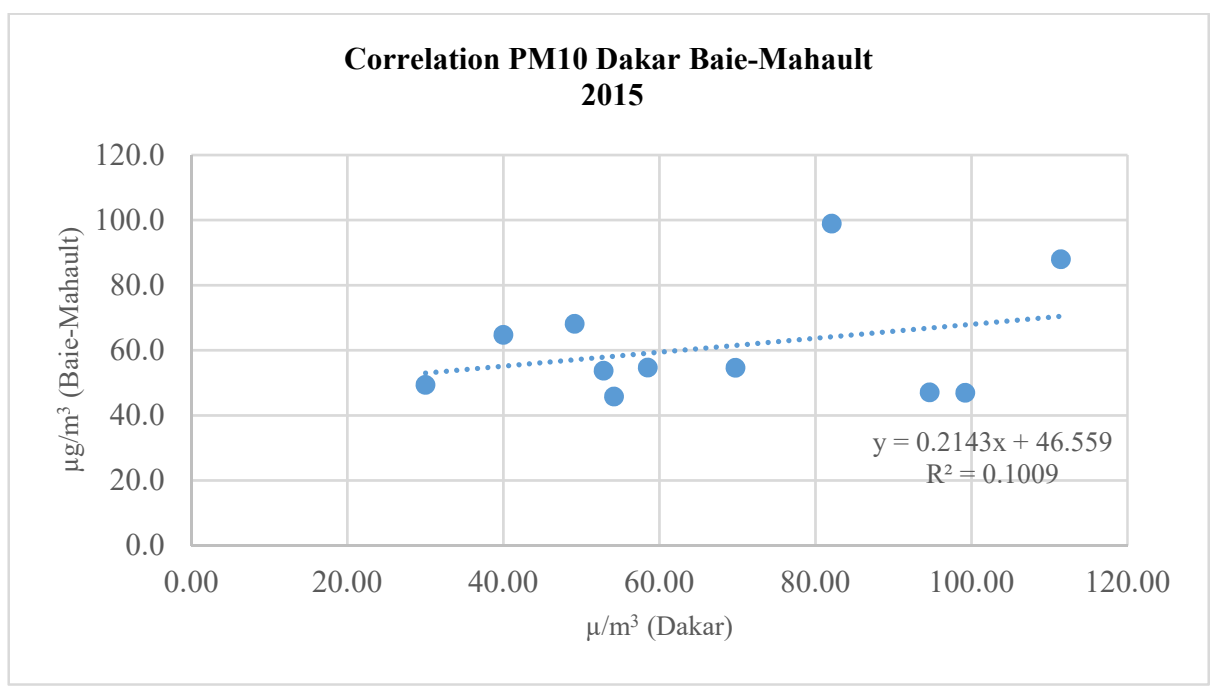

Figure 3: Guadeloupe PM10 versus Dakar PM10.

\section{RESULTS}

The correlation between Caribbean PM10 and African PM10 observed is very weak (Fig. 3). Anthropic pollution is very low in Guadeloupe $\left(\approx 20 \mu \mathrm{g} \mathrm{m}^{-3}\right)$, and for the Dakar PM10 measurements taken at a station location, a car traffic lower impact area had been chosen. A big difference between Baie-Mahault and Dakar levels of air masses and particle mass concentrations was found. In the Caribbean, a marine boundary layer seeding by dust transported in the SAL (above $1500 \mathrm{~m}$ ) can be recorded, and on the African continent, a continental boundary layer where dust particles are injected by low-level winds and ground processes is present. The processes driving low-level dusty air masses production in both locations are very different and probably explain the absence of correlation.

\subsection{Correlation between Dakar AOT (departure) and Guadeloupe AOT (arrival)}

We studied the correlation between both AOTs of the same event. AOT concentration values for days presenting back trajectories and coherent paths between Guadeloupe and Dakar are presented in Table 2 .

Thus, a very good coefficient of correlation between AOT data from Dakar and arrival data in Baie-Mahault had been established. Fig. 4 presents the correlation between Dakar and Baie-Mahault AOTs with a coefficient of correlation $(R=0.88)$, showing a relation between AOT observed in Dakar and in Guadeloupe. The effect of low-level dust particles on Dakar AOT values affected the AOT values less than the PM10 values. This is the reason why correlation is better here than with PM10 data. AOT data more accurately reflect the presence of desert dust particles, which can account for long-range transport. Thus, AOT is the good parameter to use in Caribbean desert dust forecasting. 
Table 2: AOT (1020) data.

\begin{tabular}{|l|l|l|l|}
\hline Date & AOT (1020) Dakar & Date & AOT (1020) Guadeloupe \\
\hline $16 / 05 / 2015$ & 0.75293 & $22 / 05 / 2015$ & 0.388342 \\
\hline $07 / 06 / 2015$ & 0.641998 & $14 / 06 / 2015$ & 0.300448 \\
\hline $10 / 06 / 2015$ & 0.529815 & $16 / 06 / 2015$ & 0.151094 \\
\hline $14 / 06 / 2015$ & 4.113735 & $18 / 06 / 2015$ & 1.01983 \\
\hline $18 / 06 / 2015$ & 0.59459 & $23 / 06 / 2015$ & 0.503524 \\
\hline $20 / 06 / 2015$ & 0.897314 & $26 / 06 / 2015$ & 0.136192 \\
\hline $28 / 06 / 2015$ & 0.509802 & $03 / 07 / 2015$ & 0.293344 \\
\hline $07 / 07 / 2015$ & 0.267146 & $14 / 07 / 2015$ & 0.30775 \\
\hline $17 / 07 / 2015$ & 0.346008 & $21 / 07 / 2015$ & 0.153456 \\
\hline $18 / 07 / 2015$ & 0.373166 & $23 / 07 / 2015$ & 0.261688 \\
\hline $21 / 07 / 2015$ & 1.037439 & $28 / 07 / 2015$ & 0.355897 \\
\hline $10 / 08 / 2015$ & 0.480241 & $21 / 08 / 2015$ & 0.186805 \\
\hline
\end{tabular}

\section{CONCLUSION}

In this study, we quantified a relation between dust-level measurements at the departure of dust events over the African coast and at their arrival on Guadeloupe, a Caribbean island.

The presence of a large amount of mineral dust at low levels in Dakar affects the PM10 data too greatly. The low-level particles cannot travel over the $4000 \mathrm{k}$ of ocean. Thus, we have a bad correlation coefficient between the PM10 data for Dakar and Guadeloupe.

Using the AOT data of Dakar and Guadeloupe, a good correlation coefficient due to less impact of low-level dust on Dakar AOT was obtained. Using AOT measurements, a better account taken of dust presence over Dakar in the SAL is likely, which aids their long-range transport over the Atlantic Ocean.

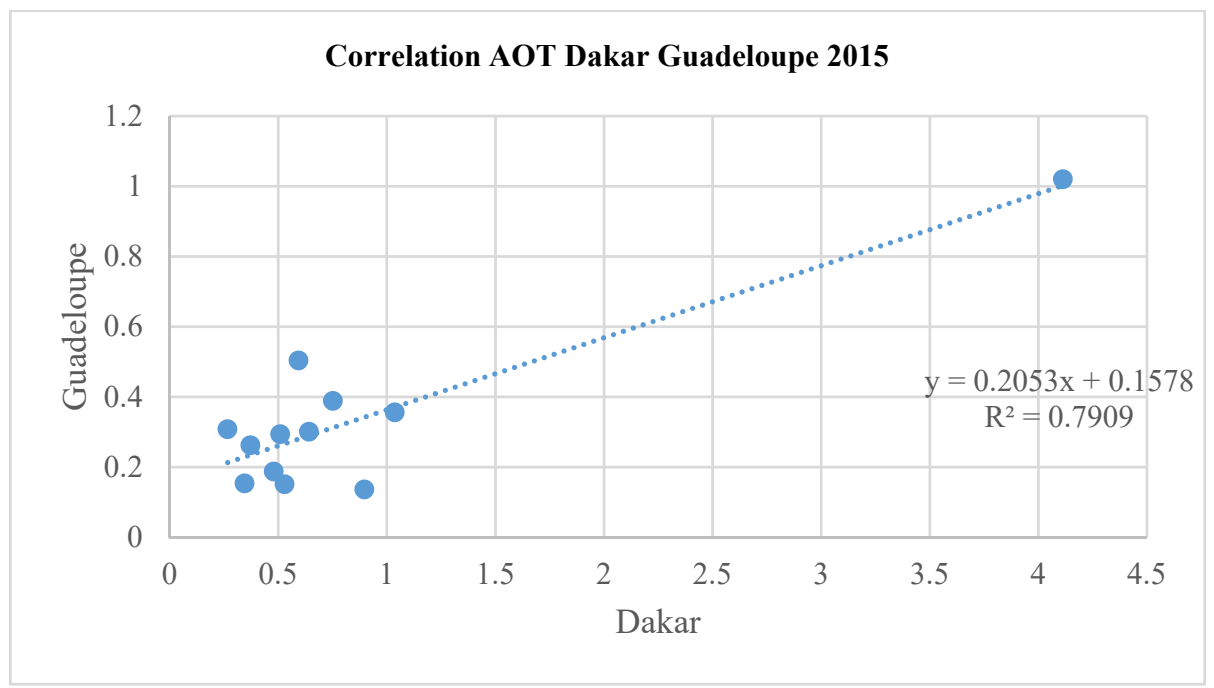

Figure 4: Guadeloupe AOT versus Dakar AOT. 


\section{REFERENCES}

[1] Zender, C.S., Bian, H. \& Newman, D., Mineral dust entrainment and deposition (dead) model: Description and 1990s dust climatology. Journal of Geophysical Research: Atmospheres, 108, 2003.

[2] Schepanski, K., et al., Meteorological processes forcing Saharan dust emission inferred from MSG-SEVIRI observations of subdaily dust source activation and numerical models. Journal of Geophysical Research: Atmospheres, 114, 2009.

[3] Chiapello, I., Bergametti, G., Chatenet, B., Bousquet, P., Dulac, F. \& Soares, E.S., Origins of African dust transported over the northeastern tropical Atlantic. Journal of Geophysical Research: Atmospheres, 102, pp. 13701-13709, 1997.

[4] Prospero, J.M., Ginoux, P., Torres, O., Nicholson, S.E. \& Gill, T.E., Environmental characterization of global sources of atmospheric soil dust identified with the Nimbus 7 Total Ozone Mapping Spectrometer (TOMS) absorbing aerosol product. Reviews of Geophysics, 40, 2002.

[5] Rodriguez, S., et al., Modulation of Saharan dust export by the North African dipole. Atmospheric Chemistry and Physics, 15, pp. 7471-7486, 2015.

[6] Adams, A.M., Prospero, J.M. \& Zhang, C., CALIPSO-derived three-dimensional structure of aerosol over the Atlantic Basin and adjacent continents. Journal of Climate, 25, pp. 6862-6879, 2012.

[7] Carlson, T.N. \& Prospero, J.M., The large-scale movement of Saharan air outbreaks over the northern equatorial Atlantic. Journal of Applied Meteorology, 11, pp. 283-297, 1972.

[8] Prospero, J.M. \& Carlson, T.N., Vertical and areal distribution of Saharan dust over the western equatorial North Atlantic Ocean. Journal of Geophysical Research, 77, pp. 5255-5265, 1972.

[9] Kaufman, Y.J., Koren, I., Remer, L.A., Tanré, D., Ginoux P. \& Fan, S., Dust transport and deposition observed from the Terra-Moderate Resolution Imaging Spectroradiometer (MODIS) spacecraft over the Atlantic Ocean. Journal of Geophysical Research: Atmospheres, 110, 2005. 